\section{EREM 77/3}

Journal of Environmental Research, Engineering and Management Vol. 77 / No. 3 / 2021 pp. 74-85

DOI 10.5755/j01.erem.77.3.24734
Experimental Studies on Effects of Selected Species of Fungi on Aerobic Composting of Sugar Pressmud

Received 2019/11

Accepted after revision 2021/06

\title{
Experimental Studies on
} Effects of Selected Species of Fungi on Aerobic Composting of Sugar Pressmud

\author{
Amar S. Byakodi*
}

Assistant Professor, Department of Civil Engineering, Angadi Institute of Technology and Management, Belagavi

\section{Dr. B.T. Suresh Babu}

Professor, Department of Civil Engineering, Angadi Institute of Technology and Management, Belagavi

\section{*Corresponding author: amarsbenv@gmail.com}

Pressmud is one of the most highly complex organic by-products generated from sugar industry. Due to its complex nature, disposal of the pressmud is difficult without affecting the surrounding environment. Pressmud has a high potential of converting itself into a good quality organic manure with proper management, through the aerobic composting process. This study is a part of major research work which focuses on recycling of nutrients and safe disposal of two of the most complex by-products: sugar pressmud and distillery spent wash through the aerobic composting process. The main objective of this study is to determine the effect of a commercially available microbial consortium on aerobic composting of pressmud. The selected microbial consortium includes four species of fungi: Phaenerochaete, Trichoderma Virdea, Aspergillus Niger, Pleurotus. These are capable of degrading complex organic matter with lignocellulosic characteristics. Five composting mixtures were prepared for this study, with four composting mixtures of individual species of fungus and the fifth composting mixture with all four fungi species. Aerobic composting was carried out in PVC reactors with $7 \mathrm{~kg}$ of pressmud as a base material, $1 \%(\mathrm{w} / \mathrm{w}$ ) of optimum dosage for microbial 
consortium and 5\% (w/w) of digested cow dung. The study was carried in the pre-monsoon season over a period of 50 days. Aeration was provided with mixing of the contents at every three days interval, and also, water was added to maintain the moisture content in the optimum range. Representative samples were collected and analyzed for various physic-chemical parameters. Further, these results were compared with the standards prescribed by Fertilizer Control Order (FCO), Ministry of Agriculture, Government of India, to assess the nutrient content of the prepared compost. The prepared compost from CM-V showed a pH of 7.62, EC of $3.67 \mathrm{dS} / \mathrm{m}$, TOC of $17.64 \%$, TKN of $2.24 \%$, phosphorus of $4.93 \%$, potassium of $1.11 \%$, iron of $72.20 \mathrm{mg} / \mathrm{kg}$ and $\mathrm{C} / \mathrm{N}$ ratio of 7.86 . Hence, it can be concluded that CM-V has satisfactory overall nutrient content in most of the parameters. But further studies are to be conducted in a large scale to assess the evolution of heat during the composting process and its effects on duration of composting.

Keywords: Pressmud, Composting, Fungi, Waste by-product.

\section{Introduction}

India is an agro-based country with most of the rural population depending on agriculture. India is second in production of sugar, with Brazil in the first place. Sugar can be extracted from two major sources namely beet and sugarcane, the latter being used for sugar production in India. Around 525 sugar industries are registered in India with a production capacity of 4,110 lakh tonnes (2018-2019) (Indian Sugar Mill, 2019). Due to the significance of sugar in everyday aspect, sugarcane is grown in an area of around five million hectares. Karnataka has 59 sugar industries with an annual production capacity of 5.65 lakh tonnes. Similarly, Belagavi district has 22 sugar industries with an annual production capacity of 1.00 lakh tonnes of sugar (S. Nijalingappa Sugar Institute, 2020).

Harvested sugarcane in the sugar industry is washed with hot water and then passed through a milling section, where juice is extracted. Juice is then clarified using lime to remove suspended particles, and sulphur dioxide gas is passed through the juice to bleach and remove the colour. The clarified and bleached juice is then passed through a number of evaporators, where the moisture content from juice is reduced and finally thick syrup, called massecuite, is produced. Further, it is then passed through a crystallizer centrifuge to produce sugar crystals. During the production of sugar, many by-products are generated viz; bagasse, pressmud, or molasses along with wash water. Bagasse is produced at the rate of 28 $\%$ to $30 \%$ of sugarcane crushed. Similarly, pressmud and molasses are generated at the rate of $3 \%$ to $4 \%$ of sugarcane crushed (Bhat et al., 2017). The quantum of these by-products generated is huge and the disposal is a difficult task due to their high pollution potential.

These by-products due to their inherent properties have a potential for recycling the nutrient content with proper handling and treatment techniques. Bagasse is used as raw material for paper and pulp industries, as well as a feed stock for animals. Molasses is used as raw material for production of ethyl alcohol in distilleries. Pressmud is one of the significant by-products of the sugar industry and is organic in nature. It is a soft, amorphous, dark brown coloured material with minimal sugar content, fibres, colloids, cane wax, albuminoids, inorganic salts and soil particles. A typical composition of pressmud is shown in Table 1.

Table 1. Typical characteristics of sugarcane pressmud

\begin{tabular}{c|c|c}
\hline Sl. No. & Parameters & Percentage (\%) \\
\hline 1. & Moisture content & $70-75$ \\
\hline 2. & Fibre content & $20-30$ \\
\hline 3. & Crude wax & $7-15$ \\
\hline 4. & Sugar & $0.9-1.5$ \\
\hline 5. & Crude Protein & $5-10$ \\
\hline 6. & Nitrogen & $2-2.50$ \\
\hline 7. & Lignin & $9.0-9.3$ \\
\hline 8. & Cellulose & $10.5-11.4$ \\
\hline 9. & Hemi-cellulose & $9-10$ \\
\hline
\end{tabular}


The present study is a part of bigger research work on developing a suitable treatment technique for proper handling and management of complex waste, as well as for recycling their nutrient potential. Sugar industry pressmud and distillery spentwash are considered as base materials for the research work. The main objective of this research work is to reduce the pollution potential of these complex wastes through an aerobic composting process and effective utilization of the prepared compost for growth of selected crops. The entire research work is divided into four phases and the present study is phase - I of the research work.

The main objective of this present study is to determine the feasibility of a commercially available microbial consortium on composting of sugar pressmud. Experimental studies have been carried out to observe the variations in physic-chemical properties of the prepared compost and compare with the standard prescribed by the Fertilizer Control Order (FCO), Ministry of Agriculture, Government of India.

\section{Material and Methodology}

The present study was carried out at the Research Centre of Angadi Institute of Technology and Management, Belagavi, Karnataka. The base material for the composting process, pressmud, was collected from Doodhaganga Krishna Sahakari Sakkare Karkhana Niyamat, Chikodi, Karnataka. The selected microbial consortium was collected from the University of Agricultural Science, Dharwad, Karnataka, and is available as a commercial

Fig. 1. Microbial consortium (powered form) used in composting (a) Phaenerochaete, (b) Trichoderma Virdea, (c) Aspergillus Niger, (d) Pleurotus

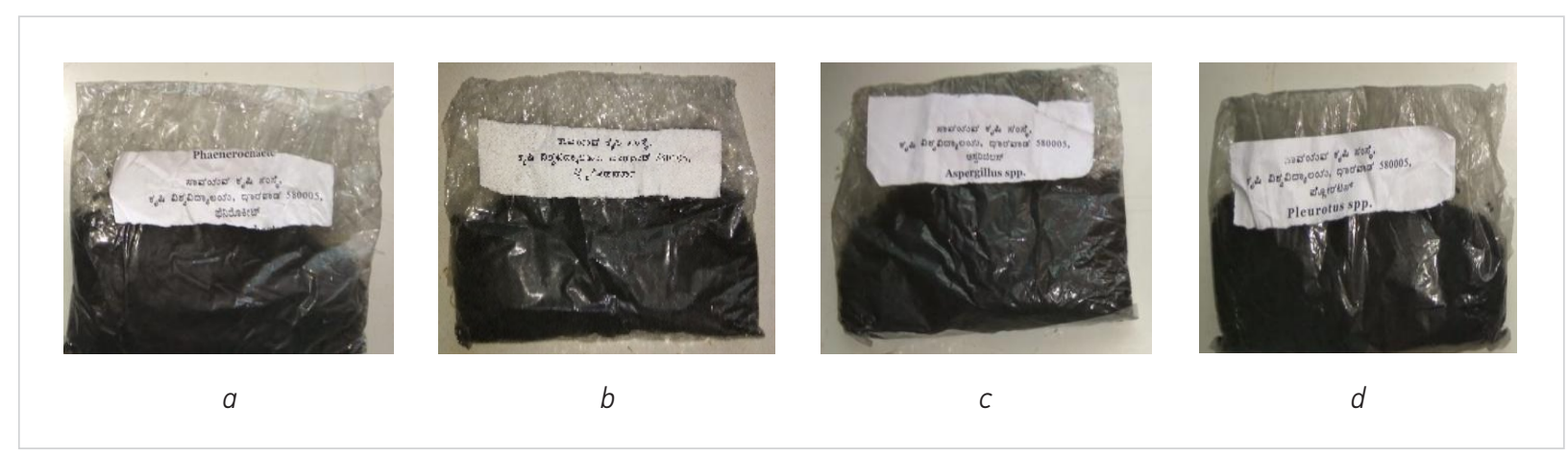

product for degrading organic waste. The microbial consortium is in the form of black powder and is shown in Fig. 1. It contains a mixture of spores of microorganisms along with nutrients required for their growth. Further, digested cow dung is collected locally.

Microorganisms play an important role in the compositing process. The selected microbial consortium consists of various species of fungi including Phaenerochaete, Trichoderma Virdea, Aspergillus Niger, and Pleurotus. These are favourable for degrading the highly complex organic waste, and the characteristics of these fungi are discussed below.

Phanerochaete is one of the resupinate or crust fungi which decays wood. Phanerochaete produces a lignin degrading enzyme making it important. This is also one of the white rot fungi which degrades lignin and leaves cellulose behind. Many of the white rot fungi exist, but Phanerochaete has several characteristics making it very useful. Unlike most of the white rot fungi, this species leaves the cellulose of the degrading matter untouched and it has a very high optimum temperature of about $40^{\circ} \mathrm{C}$, indicating that it can survive in composting heaps. Trichoderma Virdae is of great importance for degradation of complex organic matter due to its lygnolytic, cellulolytic and saprophytic in nature. Trichoderma utilizes carbon of the bio-molecules from the organic materials for its growth and survival, and it leaves behind the phosphorus, potassium and sulphur, thus increasing these levels in compost. Trichoderma virdae has been identified to degrade paper with a lignocellulose complex and 
other polymeric materials. Further, it is also effective in producing phospho-compost (Sharma et al., 2012).

Aspergillus Niger is one of the most common species of microorganisms found in the environment. These exists as saprophytes indicating that they extract nutrition from a variety of dead and decaying material such as leaves, fruits and other vegetation. Due to the abundance of their nutritional sources, they are readily available in a wide variety of areas. Aspergillus Niger forms black or brown spores, which provide protection from sunlight and UV radiation, also giving this a competitive advantage in most habitats (Gaur et al., 1982). Pleurotus is commonly known as oyster mushrooms, considered as white rot fungi for their mycelium. Pleurotus has a shorter growth period at temperatures varying from $20^{\circ} \mathrm{C}$ to $30^{\circ} \mathrm{C}$ with a $55 \%$ to $70 \%$ moisture on different lignocellulosic substrates. Pleurotus is one of the most efficient white rot fungi and is able to degrade wood and non-composted lingo-cellulosic materials (Julian et al., 2019).

The pressmud was dried in open atmosphere to remove excess moisture content and then was used as a base material for composting. Five variations of the experimental work were carried out with different species of the selected microbial consortium. The $c$ Composition of the composting mixture and species of microorganisms utilized for the study are indicated in Table 2. Further, the physic-chemical characteristics of the end product of the composting process were compared with the standards prescribed by the Fertilizer Control Order (FCO), Ministry of Agriculture, Government of India, for assessing its nutrient content (Ministry of Agriculture, 1985).

Table 2. Composition of composting mixtures

\begin{tabular}{c|c|c}
\hline Composting Mixture & $\begin{array}{c}\text { Composition } \\
\mathrm{PM}^{*}+\mathrm{CD}^{*}+\mathrm{MC}^{*}\end{array}$ & Microbial Culture \\
\hline $\mathrm{CM}-\mathrm{I}$ & $7 \mathrm{~kg}+350 \mathrm{gm}+70 \mathrm{gm}$ & Phaenerochaete \\
\hline $\mathrm{CM}-\mathrm{II}$ & $7 \mathrm{~kg}+350 \mathrm{gm}+70 \mathrm{gm}$ & Trichoderma Virdea \\
\hline $\mathrm{CM}-\mathrm{III}$ & $7 \mathrm{~kg}+350 \mathrm{gm}+70 \mathrm{gm}$ & Aspergillus Niger \\
\hline $\mathrm{CM}-\mathrm{IV}$ & $7 \mathrm{~kg}+350 \mathrm{gm}+70 \mathrm{gm}$ & Pleurotus \\
\hline$C M-V$ & $7 \mathrm{~kg}+350 \mathrm{gm}+70 \mathrm{gm}$ & All four species of fungi \\
\hline
\end{tabular}

${ }^{*} P M$ - pressmud, $C D$ - cow dung, $M C$ - microbial consortium, ${ }^{\#} \mathrm{CM}$ - composting mixture

\section{Experimental Setup}

Composting of pressmud was carried out in PVC reactors with the top diameter of $0.42 \mathrm{~m}$ and the bottom diameter of $0.18 \mathrm{~m}$ with a depth of $0.23 \mathrm{~m}$. Pressmud of $7 \mathrm{~kg}$ was used as base material for the composting process, and 5 $\%$ by weight of digested cow dung was added to the composting mixture along with water. Similarly, the optimum dosage of the microbial consortium was $1 \%$ by weight, and was added to the composting mixture as indicated in Table 2. Moisture content in the experimental setup was maintained between $65 \%$ to $75 \%$ to provide favourable conditions for the composting process.
All the five composting mixtures were setup identically for the composting process and were kept in open atmosphere as indicated in Fig. 2. Frequency of application of water was fixed at every three days, during which entire contents of the composting heaps were mixed to provide proper aeration. Temperature of the composting heap was measured on a daily basis to monitor the evolution of heat in a composting heap. The present study was carried for a duration of 50 days in the pre-monsoon season from March to May, and the atmospheric temperature during the study period varied from $26^{\circ} \mathrm{C}$ to $34^{\circ} \mathrm{C}$. 
Fig. 2. Experimental setup for composting of pressmud using PVC reactors. Species of fungi used (a) Phaenerochaete, (b) Trichoderma Virdea, (c) Aspergillus Niger, (d) Pleurotus, (e) combination of all four fungi species

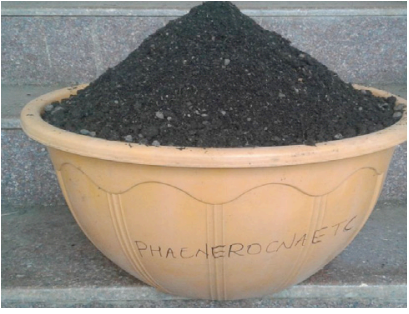

$a$

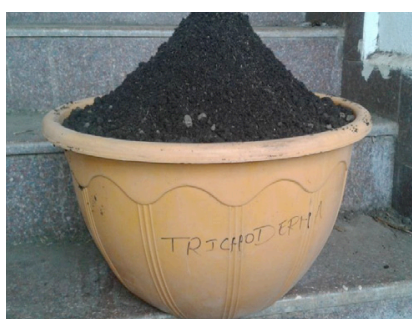

$b$

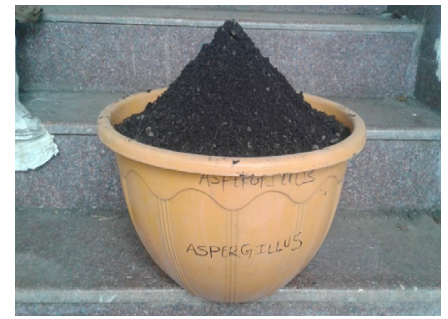

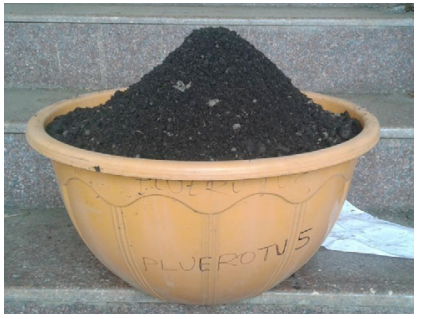

d

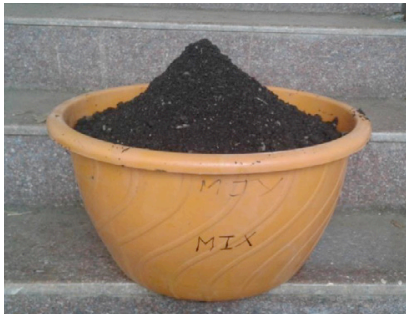

\section{Results and Discussion}

Pressmud is one of the complex by-products generated form sugar industry and is highly organic in nature. The collected fresh pressmud was analyzed for its physic-chemical properties and the results are provided in Table 3. Pressmud has a pH of 6.25 , electrical conductivity of $1.96 \mathrm{dS} / \mathrm{m}$, moisture content of $72.50 \%$, total organic carbon of $12.53 \%$, total kjeldahl nitrogen of 0.48 $\%, \mathrm{C} / \mathrm{N}$ ratio of 25.95 , phosphorus of $0.40 \%$, potassium of $1.09 \%$ and iron of $0.15 \mathrm{mg} / \mathrm{kg}$. These results were at par with the observation made by other researchers (Bhat et al., 2017; Satisha and Devarajan, 2007).

The Fertilizer Control Order (FCO), Ministry of Agriculture, Government of India, has prescribed the standards for nutrient requirements for various types of composts and fertilizers. These standards provide a minimum or maximum range of physic-chemical properties that need to be adhered for an optimum nutrient composition in a compost and are given in Table 3. As per the $\mathrm{FCO}$, the organic compost should have a pH of 6.5 to
7.5, and electrical conductivity must be less than 4 $\mathrm{dS} / \mathrm{m}$. Similarly, total organic carbon should be more than $12 \%$, total kjeldahl nitrogen should be over 0.80 $\%$, phosphorus and potassium should exceed $0.40 \%$, and $\mathrm{C} / \mathrm{N}$ ratio must be less than 20 . Individually, these parameters cannot be used for determining the quality of compost, but three or more parameters together can provide an accurate conclusion.

All the composting mixtures were prepared as per the experimental setup described in the previous section. Representative samples were collected and analyzed at days $0,15,25$ and 50 for all composting mixtures. During the experimentation, evolution of temperature was not significant in any of the composting mixtures. This was due to the higher surface area compared with its size; besides, frequent mixing of composting mixtures for aeration caused dissipation of heat. Further, there was no development of mycelium in any of the composting mixtures. 
Table 3. Characteristics of pressmud and $F C O$ standards

\begin{tabular}{c|c|c|c|c}
\hline Sl. No. & Parameter & Fresh Pressmud & FCO Prescribed Standards & Unit \\
\hline 1 & $\mathrm{pH}$ & 6.25 & 6.5 to 7.5 & - \\
\hline 2 & Electrical Conductivity & 1.96 & $<4.0$ & $\mathrm{dS} / \mathrm{m}$ \\
\hline 3 & Moisture Content & 72.50 & 15 to 25 & $\%$ \\
\hline 4 & Total Organic Carbon & 12.53 & $>12.00$ & $\%$ \\
\hline 5 & Total Kjeldhal Nitrogen & 0.48 & $>0.80$ & $\%$ \\
\hline 6 & Total Phosphorus & 0.40 & $>0.40$ & $\%$ \\
\hline 7 & Total Potassium & 1.09 & $>0.40$ & $\%$ \\
\hline 8 & C/N Ratio & 25.95 & $<20$ & $\%$ \\
\hline 9 & Iron & 0.15 & - & $\mathrm{mg} / \mathrm{kg}$ \\
\hline
\end{tabular}

$\mathrm{pH}$ is an effective indication for observing the activity of microorganisms in composting of pressmud. The $\mathrm{pH}$ of fresh pressmud was 6.25, and the addition of microbial consortium and digested cow dung increased the $\mathrm{pH}$ slightly in all the composting mixtures at the end of 15 days. CM-II showed a maximum $\mathrm{pH}$ of 7.16 and $\mathrm{CM}-\mathrm{I}$ showed a minimum $\mathrm{pH}$ of 6.96. Similarly, the $\mathrm{pH}$ marginally increased in $\mathrm{CM}-\mathrm{I}$ and $\mathrm{CM}-\mathrm{V}$ for the period of 25 days, whereas other composting mixtures showed a slight reduction. The maximum $\mathrm{pH}$ was observed in $\mathrm{CM}-\mathrm{V}$ with 7.38 and the minimum value was observed in CM-IV with 6.97. Further, the $\mathrm{pH}$ reduced in $\mathrm{CM}-\mathrm{I}, \mathrm{CM}-\mathrm{II}$ and $\mathrm{CM}-\mathrm{III}$ to $6.95,6.21$ and 6.78 , respectively, at the end of 50 days.

These variations observed during the study were similar to studies conducted by other researchers (Bhat et al., 2017; Satisha and Devarajan, 2007). An increase in

Fig. 3. Variation of $\mathrm{pH}$ w.r.t. composting mixtures

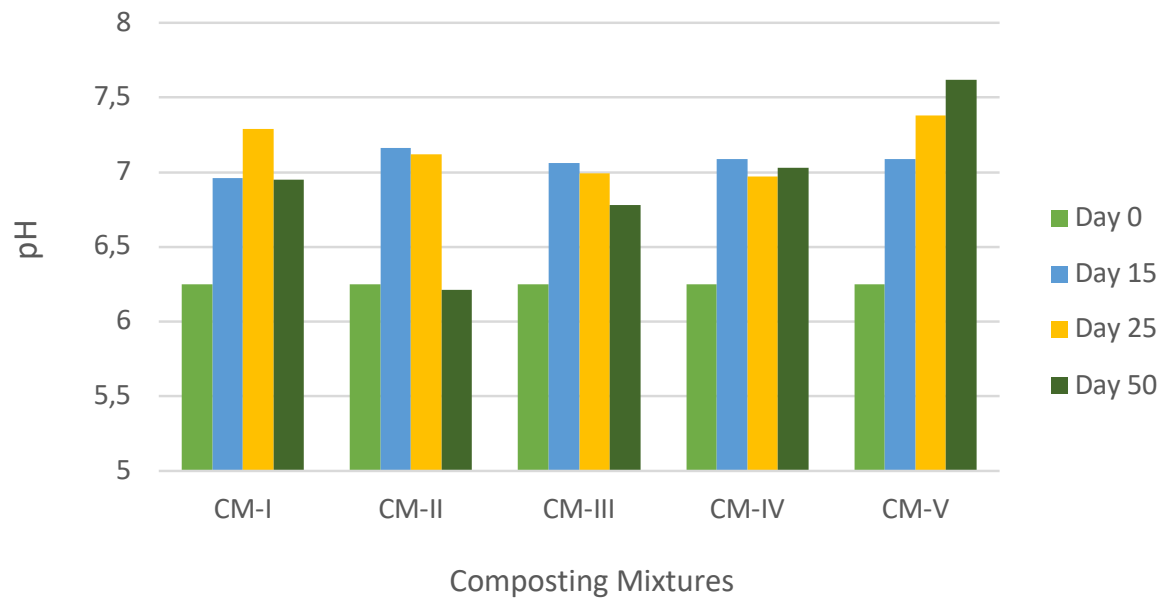


$\mathrm{pH}$ until 15 days was due to metabolic degradation of organic acids or loss by volatilization of ammonia compounds due to degradation of protein. A reduction in $\mathrm{pH}$ at a later stage of the composting period might be due to the formation of new organic acids and production of phenolic compounds indicating an increase in mineral nutrients of the final product. During the entire study period, the $\mathrm{pH}$ of all the composting mixtures was maintained near to neutral without significant variation. This indicates favourable conditions maintained for the development of microorganisms.
Electrical conductivity (EC) of a composting pile indicates the ionic exchange capacity of the base material. Fresh pressmud showed EC of $1.96 \mathrm{dS} / \mathrm{m}$, and the addition of the microbial consortium and digested cow dung increased the EC in all composting mixtures except CM-I. The maximum EC was observed in $\mathrm{CM}-\mathrm{III}$ with $2.76 \mathrm{dS} / \mathrm{m}$ and the minimum EC was observed in CM-I with $1.65 \mathrm{dS} / \mathrm{m}$ at the end of 15 days. Further, the EC decreased in all the composting mixtures except in $\mathrm{CM}-\mathrm{V}$ at the end of 25 days. The minimum EC was observed in $\mathrm{CM}-\mathrm{I}$ with $1.59 \mathrm{dS} / \mathrm{m}$. As the composting process continued, all the composting

Fig. 4. Variation of EC w.r.t. composting mixtures

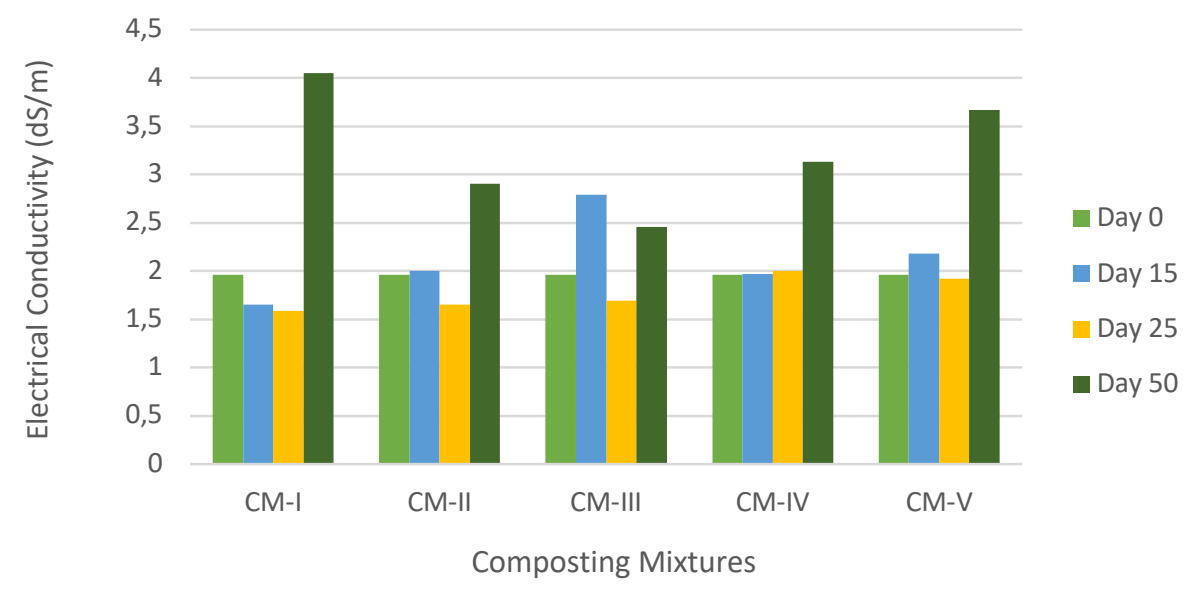

Fig. 5. Variation of TOC w.r.t. composting mixtures

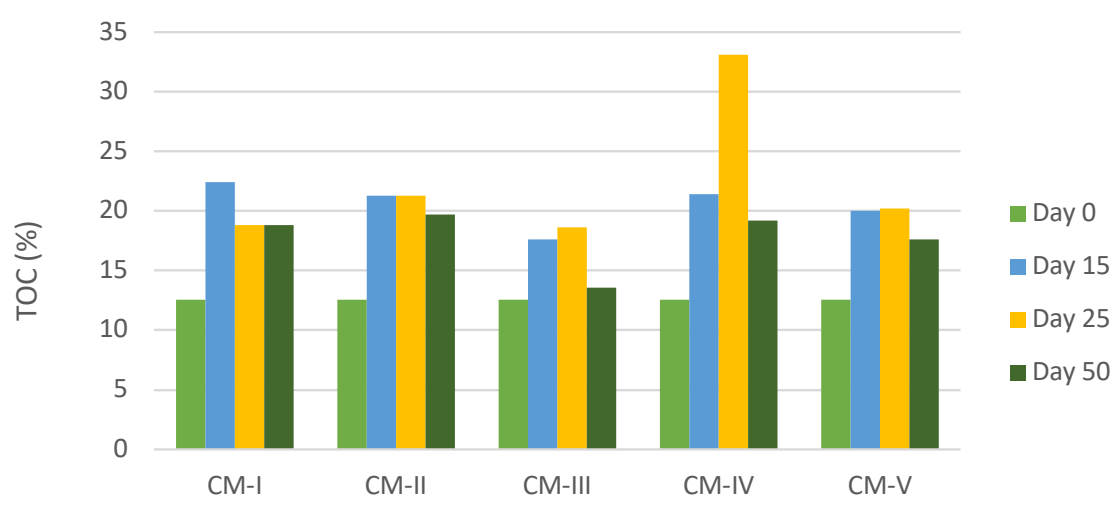

Composting Mixtures 
mixtures showed an increase in the EC with a maximum value of $4.05 \mathrm{dS} / \mathrm{m}$ in $\mathrm{CM}-\mathrm{I}$ and minimum of $2.46 \mathrm{dS} / \mathrm{m}$ in $\mathrm{CM}$-III at the end of 50 days. A decrease in EC from 15 days to 25 days is indicative of degradation of organic matter and is similar to observations made by many researchers (Kumar et al., 2010; Raj and Antil, 2011; Satisha and Devarajan, 2007; Zhang and Sun, 2017). Thereafter, a gradual increase in $\mathrm{EC}$ is due to the mineralization of nutrients in the final stage of composting.

Total organic carbon (TOC) indicates the readily available carbonaceous matter present in a composting pile. Fresh pressmud has a TOC of $12.53 \%$, and the addition of digested cow dung increased its value in all the composting mixtures. The maximum increase was observed in CM-I with $22.45 \%$ and the minimum value of $17.59 \%$ was observed in $\mathrm{CM}-\mathrm{III}$ at the end of 15 days. Thereafter, the TOC decreased in $\mathrm{CM}-\mathrm{I}$ and $\mathrm{CM}-\mathrm{II}$, whereas other composting mixtures showed an increase values until the end of 25 days. CM-IV showed a maximum TOC of $33.11 \%$ and CM-III showed a minimum value of $18.64 \%$. Further, all the composting mixtures showed a gradual reduction in the TOC till the end of study period of 50 days. The minimum TOC of $13.6 \%$ was observed in CM-III and the maximum of $19.7 \%$ was observed in CM-II.

The initial increase in TOC is attributed to the addition of digested cow dung as it is a rich source of carbonaceous matter. In this study, due to the smaller size of composting mixtures and continuous mixing of the contents for aeration, temperature development was not significant. Hence, the thermophilic phase of the active decomposition was not clear until the end of 25 days. Similarly, a gradual reduction in the TOC from 25 days to 50 days is due to gradual degradation of organic carbon by microorganisms.

Fig. 6. Variation of TKN w.r.t. composting mixtures

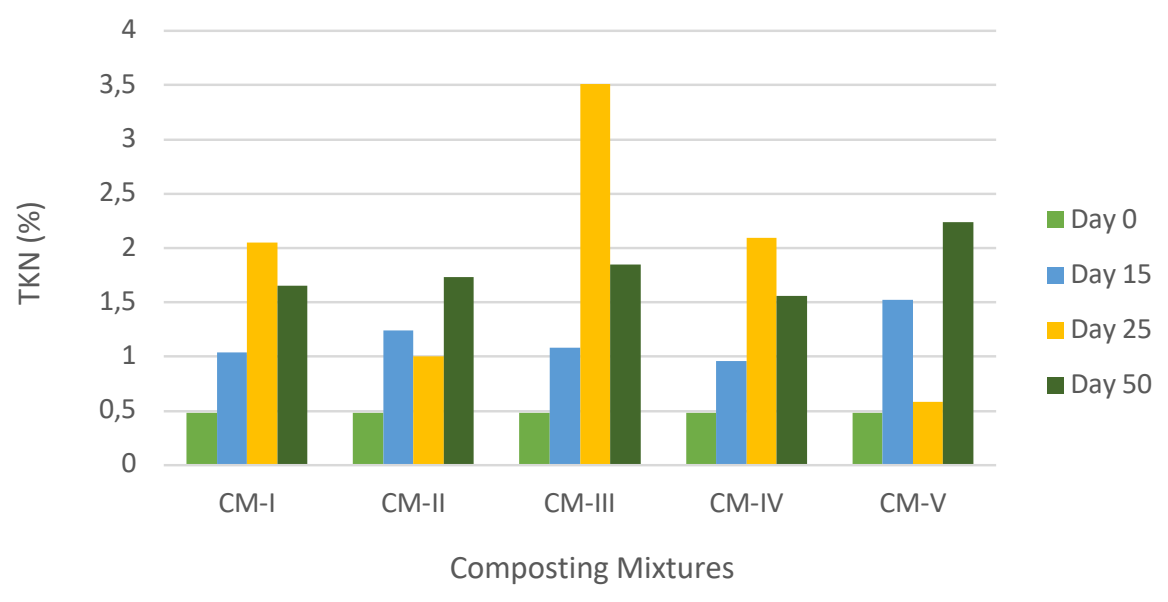

Total Kjeldahl nitrogen (TKN) indicates the amount of complex organic matter present and is one of the important nutrients in organic compost. Fresh pressmud has a TKN of $0.48 \%$, and the addition of the microbial consortium and digested cow dung increased the value of the TKN in all the composting mixtures at the end of 15 days. A maximum TKN was observed in CM-V with $1.52 \%$ and a minimum of $0.69 \%$ in CM-IV. Thereafter, CM-I, CM-III and CM-IV showed an increase in TKN and others showed a reduction. The maximum value of 3.51
\% was observed in CM-III and the minimum of $0.58 \%$ was observed in $\mathrm{CM}-\mathrm{V}$ until the end of 25 days. Further, until 50 days, CM-I, CM-III and CM-IV showed a reduction in the TKN, whereas other composting mixtures showed an increase. A maximum TKN of $2.24 \%$ was observed in $\mathrm{CM}-\mathrm{V}$ at the end of the study period.

The initial increase in the TKN until 15 days is attributed to the addition of composted cow dung and the microbial consortium. As the composting continues, CM-I, CMIII and CM-IV showed an increase in the TKN, whereas 
CM-II and CM-V showed a reduction at the end of 25 days. The decrease in the TKN is attributed to the emission of ammonia as shown by other researchers (Zhang and Sun, 2017). Thereafter, a gradual increase in TKN is due to mineralization of nitrate and stabilization of TKN in the composting mixture.

$\mathrm{C} / \mathrm{N}$ ratio represents the proportion of carbon to nitrogen, i.e., easily degradable matter to complex organic matter. Fresh pressmud has a $\mathrm{C} / \mathrm{N}$ ratio of 25.95 , which was suitable for composting. All the composting mixtures showed a reduction in the $\mathrm{C} / \mathrm{N}$ ratio at the end of 15 days. The maximum reduction was observed in $\mathrm{CM}-\mathrm{V}$ with a value of 13.16 and the maximum of 22.30 in CM-IV. Thereafter, CM-I, CM-III and CM-IV showed a reduction in the $\mathrm{C} / \mathrm{N}$ ratio, whereas $\mathrm{CM}-\mathrm{II}$ and $\mathrm{CM}-\mathrm{V}$ showed an increase at the end of 25 days. The maximum $\mathrm{C} / \mathrm{N}$ ratio was observed in $\mathrm{CM}-\mathrm{V}$ with 34.83 and the minimum of 2.31 in $\mathrm{CM}-\mathrm{III}$. Further, CM-I, CM-III and CM-V showed a reduction in the $\mathrm{C} / \mathrm{N}$ ratio at the end of 50 days. The minimum $\mathrm{C} / \mathrm{N}$ ratio of 7.22 was observed in $\mathrm{CM}-\mathrm{III}$ and the maximum was observed in CM-IV with 12.78 .

Potassium is one of the important nutrients for a compost material and fresh pressmud had a potassium of $1.09 \%$. As the composting continued, CM-I, CM-II and CM-V showed a

Fig. 7. Variation of $C / N$ w.r.t. composting mixtures

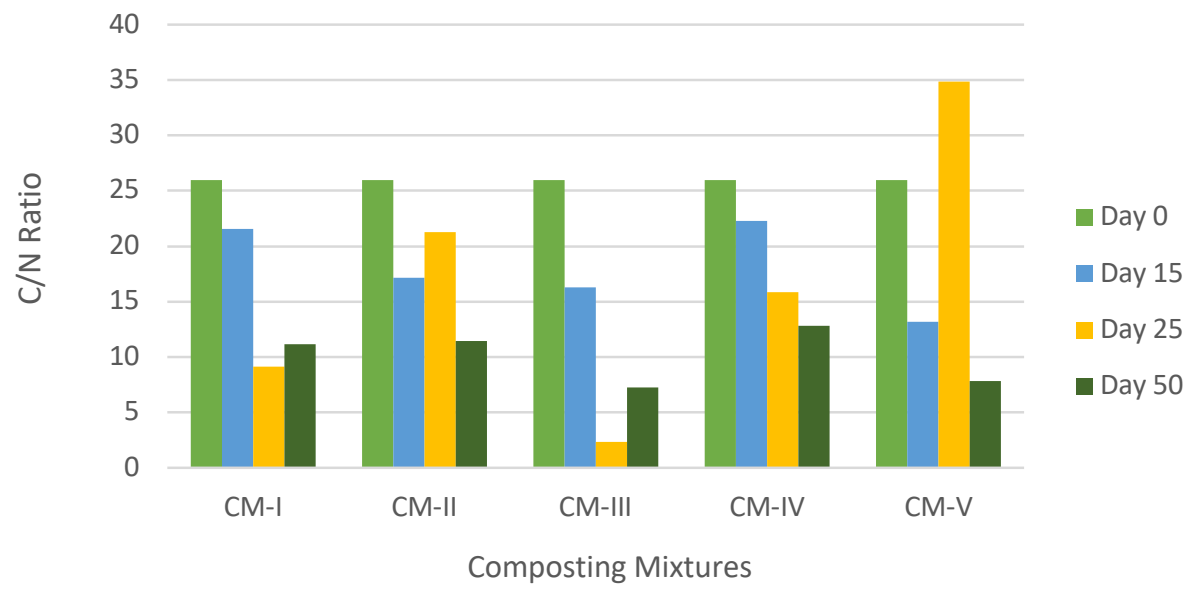

Fig. 8. Variation of potassium w.r.t. composting mixtures

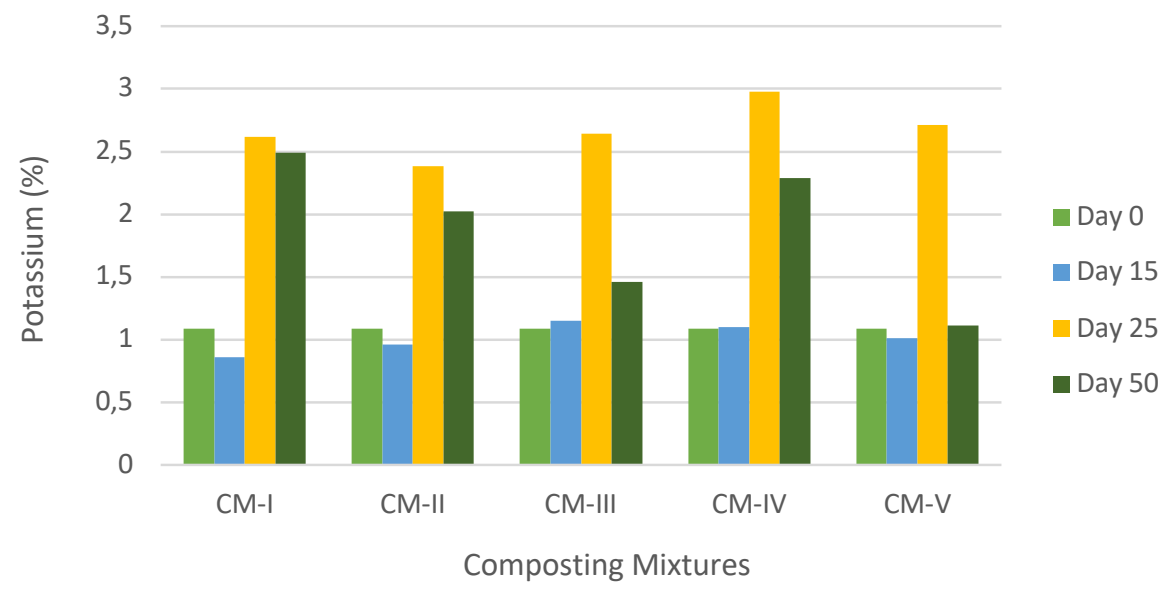


reduction in potassium at the end of 15 days. The maximum reduction was observed in $\mathrm{CM}-\mathrm{I}$ with $0.86 \%$, and this trend was in line with the variation of TOC as described earlier. All the composting mixtures showed an increasing trend until the end of 25 days with the maximum increase in CM-IV with $2.98 \%$. Further, all the composting mixtures were reduced at the end of 50 days of composting.

The variation of potassium is similar to the variations observed in TOC for CM-I, CM-II and CM-V for the entire duration of composting. Potassium during the degradation of organic matter will be the in ionic form and is evident from the variations of EC as discussed earlier. The final reduction of potassium is due to mineralization of nutrients during the final stage of composting.

Iron is one of the important micronutrients of organic compost and fresh pressmud showed a minimal of $0.15 \mathrm{mg} / \mathrm{kg}$. All the composting mixtures showed an increase in iron concentration at the end of 15 days with a maximum of $93.71 \mathrm{mg} / \mathrm{kg}$ in CM-I and a minimum of $73.33 \mathrm{mg} / \mathrm{kg}$ in CM-V. Thereafter, all the composting mixtures showed a reduction until the end of the study period of 50 days. The maximum iron concentration was observed in $\mathrm{CM}-\mathrm{V}$ with $72.20 \mathrm{mg} / \mathrm{kg}$ at the end of composting. The initial increase in iron concentration is

Fig. 9. Variation of Iron w.r.t. composting mixtures

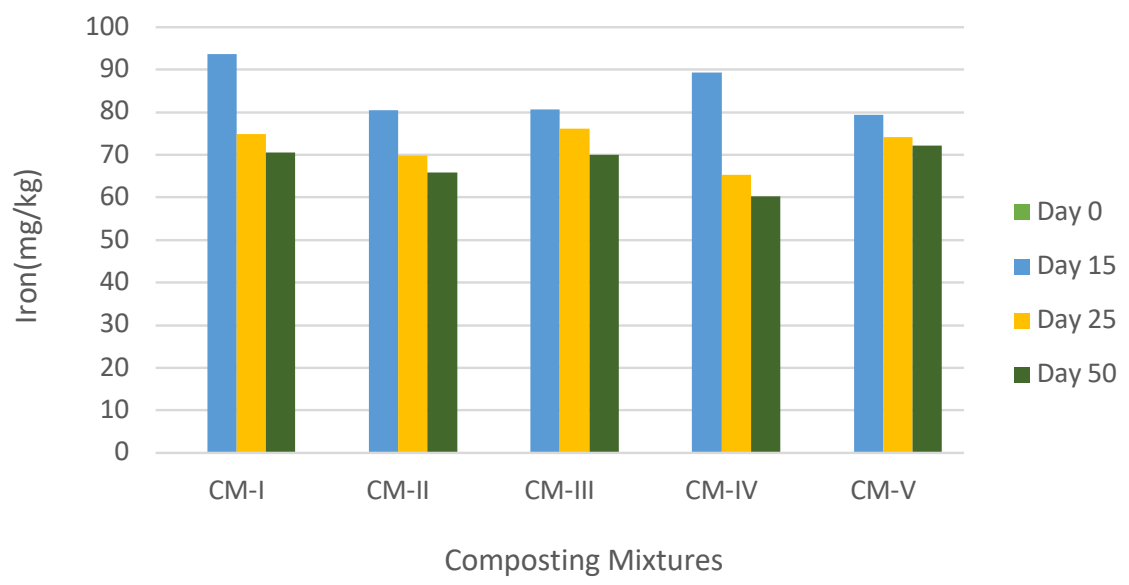

Fig. 10. Variation of moisture content w.r.t. composting mixtures

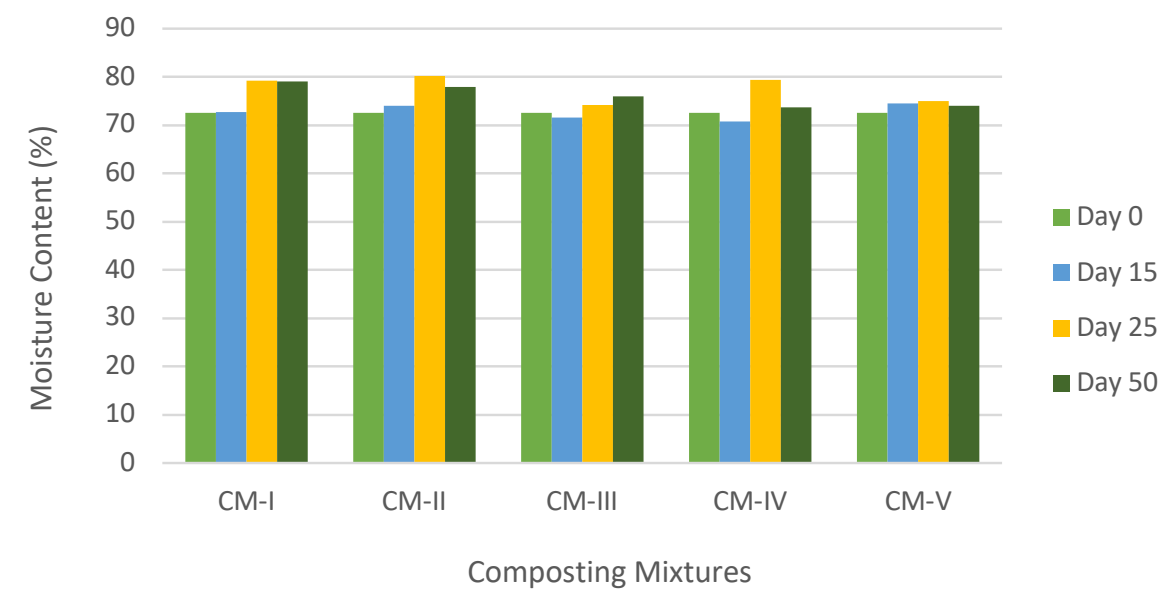


due to the addition of the microbial consortium, which increased iron in all the composting mixtures substantially. Further, the gradual reduction of iron concentration is due to mineralization of nutrient.

Moisture content of the composting heaps depends on the evaporation rate and the amount of liquid added to the composting mixtures. The study was conducted during the pre-monsoon season and, based on the evaporation rate, water was added at an interval of every three days to maintain the moisture content in favourable conditions. Since the amount of liquid added for all the composting mixture was the same, the moisture content of the heaps was the in the same range. Fresh pressmud showed a moisture content of $72.50 \%$ and throughout the study period the moisture was maintained between $70 \%$ to $80 \%$ for favourable conditions.

Phosphorus is an important macronutrient of the compost and is essential for the growth of crops. Fresh pressmud showed a phosphorus of $0.40 \%$, and as the composting continued, all the composting mixtures showed an increasing trend at the end of 15 days. Maximum phosphorus was observed in CM-III with $4.41 \%$ and the minimum of $3.36 \%$ in CM-V. Further, CM-IV and $\mathrm{CM}-\mathrm{V}$ showed a gradual increase until the end of 50 days with maximum phosphorus of $5.27 \%$ in CM-IV. This gradual increase in phosphorus is due to the continuous degradation of organic matter along with mineralization throughout the composting period.

Fig. 11. Variation of phosphorus w.r.t. composting mixtures

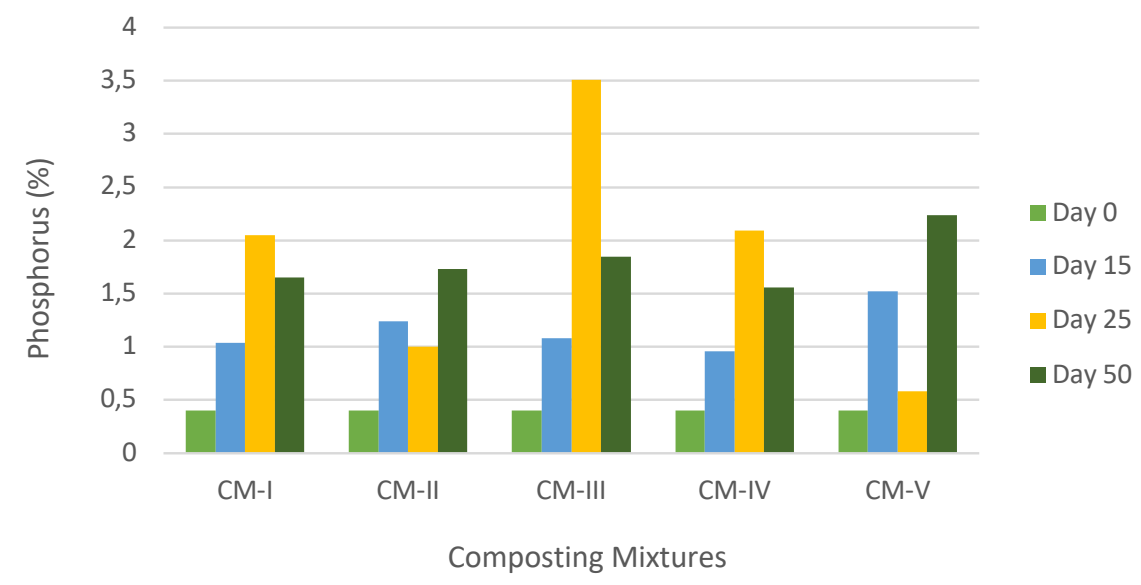

\section{Conclusions}

The experiment for composting of pressmud was carried out for a duration of 50 days. Assessment of quality of the prepared compost was made by comparing the physic-chemical parameters with the prescribed standards of the Fertilizer Control Order. As per the observed results, the overall nutrient content of $\mathrm{CM}-\mathrm{V}$ was satisfactory in most of the parameters. The end product of $\mathrm{CM}-\mathrm{V}$ showed a pH of 7.62, EC of $3.67 \mathrm{dS} / \mathrm{m}$, TOC of $17.64 \%$, TKN of $2.24 \%$, phosphorus of $4.93 \%$, potassium of $1.11 \%$, iron of $72.20 \mathrm{mg} / \mathrm{kg}$ and $\mathrm{C} / \mathrm{N}$ ratio of 7.86 . All the above mentioned values adhere to the standard prescribed by the Fertilizer Control Order. Further, utilization of all the four species of microorganisms in CM-V helps in acclimatizing in a wide variety of operating conditions and degradation of organic matter. Hence, it can be concluded that the selected microbial consortium is suitable for degradation of pressmud with optimum operating conditions. But studies have to be conducted on a large scale to assess the evolution of heat during the composting process and its effect on the duration of composting. 


\section{References}

Agarwal K.M., Barve B. R. and Khan S.S. (2012). Biogas from Pressmud, IOSR Journal of Mechanical and Civil Engineering (ISOR-JMEC), 37-41.

Bhat, S. A., Singh, J., and Vig, A. P. (2017). Amelioration and degradation of pressmud and bagasse wastes using vermitechnology. Bioresource Technology, 243, 1097-1104. https:// doi.org/10.1016/j.biortech.2017.07.093

Diaz P.M. (2016). Consequences of Compost Press Mud as Fertilizer, International Journal of advances in microbiology and Microbiological Research. 1(1), 28-30. https://doi.org/10.18831/ djmicro.org/2016011005

Gaur, A. C., Sadasivam, K. V., Mathur, R. S., and Magu, S. P. (1982). Rôle of mesophilic fungi in composting. Agricultural Wastes, 4(6), 453-460. https://doi.org/10.1016/0141-4607(82)90040-3

Indian Sugar Mill, A. (2019). Statistics details sugar industries available at, https://www.indiansugar.com/Statics.aspx (accessed 10 June 2020)

Julian, A. V., Reyes, R. G., and Eguchi, F. (2019). Agro-industrial waste conversion into medicinal mushroom cultivation. In Encyclopedia of Environmental Health (2nd ed.). Elsevier Inc. https://doi.org/10.1016/B978-0-12-409548-9.11042-5

Kumar, R., Verma, D., Singh, B. L., Kumar, U., and Shweta. (2010). Composting of sugar-cane waste by-products through treatment with microorganisms and subsequent vermicomposting. Bioresource Technology, 101(17), 6707-6711. https:// doi.org/10.1016/j.biortech.2010.03.111

Kumar S., Meena R.S., Jinger D., Jatav H.S. and Banjara T. (2017). Use of Pressmud Compost for Improving Crop productivity and Soil Health, International Journal of Chemical Studies. 5(2), 384-389.

Ministry of Agriculture, G. of I. (1985). Biofertilizers and Organic Fertilizers in Fertilizer ( Control ) Order , 1985 National Centre of Organic Farming. 1-68.

Mishra A., Khan M.Z. and Singh A. (2014). In-Situ Incorporation of Press mud Cake in Sugarcane Fields: Impact on Manorial value of Soil Environment, International Journal of Engineering Research and Technology (IJERT). 3(2), 2889-2892.

Patil M., Kavitkar M., Borkar A. and Amley S. (2010). Compost Fertilizer production from Sugar Press Mud, International Journal for Engineering Applications and Technology.
Patil N.N., Jadhav S., Ghorpode S.S. and Sharma A.B. (2013). Isolation and Enrichment of sugar Press Mud (SPM) Adapted Microorganism for Production of Biofertilizer by using Sugar Press Mud, International Journal of advanced Biotechnology and Research. 4(1), 96-104.

Raj, D., and Antil, R. S. (2011). Evaluation of maturity and stability parameters of composts prepared from agro-industrial wastes. Bioresource Technology, 102(3), 2868-2873. https:// doi.org/10.1016/j.biortech.2010.10.077

Ranveer A.C., Munde D., and Sutar S. (2015). Vermicomposting of pressmud from sugar industry, International Journal of Innovation in Engineering Research and Technology (IJIERT). 2(4), 1-10. https://doi.org/10.1016/S1365-6937(15)30307-5

Rasappan K., Kumar A. and Santosh P. (2015). Studies on sugarcane pressmud and distillery waste as Biofertilzer through Composting, International Journal of Science, 13(3), 1333-1344.

Rayudu E.S., Srimurali M. and Venkaiah K. (2018). A Study on Macronutrients of Alkaline Soil by Using Pressmud, International Journal of Scientific Research and Review. 7(1), 97-105.

Roa R.K., Sivagnanam S.K. and Sayed F.B. (2016). Isolation, Characterization and Identification of predominant Microorganisms from Agro waste, Scholar's Research library. 8(5), 79-86.

S. Nijalingappa Sugar Institute, B. (2020). Details of Sugar industries and distilleries available at, https://www.nijalingappasugar.com/guidelines.html (accessed 10 June 2020)

Satisha, G. C., and Devarajan, L. (2007). Effect of amendments on windrow composting of sugar industry pressmud. Waste Management, 27(9), 1083-1091. https://doi.org/10.1016/j.wasman.2006.04.020

Sharma, B. L., Singh, S. P., and Sharma, M. L. (2012). Bio-degradation of Crop Residues by Trichoderma Species vis-à vis Nutrient Quality of the Prepared Compost. Sugar Tech, 14(2), 174-180. https://doi.org/10.1007/s12355-011-0125-x

Venkatesh D. and Venkateswarlu M. (2010). An overview of Indian Sugar Industry, BIMS International Journal of Social Science and Research. 11-12.

Zhang, L., and Sun, X. (2017). Using cow dung and spent coffee grounds to enhance the two-stage co-composting of green waste. Bioresource Technology, 245(August), 152-161. https:// doi.org/10.1016/j.biortech.2017.08.147 